\title{
ORGANIZACION DEL ARCHIVO ESPECIAL DEL INVENTARIO DE BIENES DE LAS CORPORACIONES LOCALES
}

651.5:352.711 (46)

\author{
Por \\ Daniel Cremades Cerdán \\ Encargado del Inventario de Bienes del Ayuntamiento de Murcia
}

SUMARIO: I. INTRODUCCION. - II. ARCHIVADORES METALICOS TIPO AF.-III. FICHERO.-IIV. PLANOS DE SITUACION DEL MUNICIPIO.-V. CARPETA PARA EL ARCHIVO DE PLANOS ORIGINALES.-VI. FICHA-CARPETA.

\section{INTRODUCCION}

El Reglamento de Bienes, en sus artículos 16 al 35, contiene las normas que regulan el Inventario y Registro de los Bienes.

Existe en esta normativa un auténtico desequilibrio entre los artículos dedicados al Libro-Inventario, propiamente dicho, con exhaustiva regulación de epígrafes y datos exigibles a cada uno de ellos, en oposición a la ausencia, prácticamente, de normas a que debiera someterse el archivo especial del inventario de bienes.

Solamente el artículo 29 hace referencia al mismo, estableciendo que "todos los documentos que refrendaren los datos del Inventario, y en especial los títulos de dominio, actas de deslinde y valoración, planos y fotografías, se archivarán con separación de la demás documentación municipal». Y que «al inventariar cada uno de los bienes se consignará, como último dato, la signatura del lugar del archivo en que obrare la documentación correspondiente». 
Indudablemente, esta ausencia de regulación en el Reglamento de Bienes para la organización del archivo especial del inventario, básico en la acción administrativa, ha dado lugar a que esta parcela de tan enorme responsabilidad, como es la conservación, defensa y tutela de los bienes de las Corporaciones locales, sea frecuentemente la que ofrezca una mayor confusión y desorganización en los grandes Municipios.

Ahora bien, dado que el artículo 29 del Reglamento de Bienes, aunque no establezca una organización determinada, prescribe que los documentos correspondientes a los bienes se archivarán con separación de la demás documentación municipal, sin más condicionamiento, lógicamente, existe libertad para organizar este archivo especial de acuerdo con el criterio que se considere más conveniente.

En este sentido, y estando la Administración pública tan precisada de asimilar y adaptar continuamente las técnicas empresariales, entiendo que en la actualidad, y sin detrimento de las grandes posibilidades que a todos los efectos ofrecen los ordenadores electrónicos, la organización del archivo especial del inventario se puede conseguir eficazmente con los siguientes elementos:

\section{ARCHIVADORES METALICOS TIPO AF}

Para este archivador será necesario utilizar igualmente los accesorios, carpetas y subcarpetas del tipo AF. Cada una de estas carpetas contendrán solamente la documentación de cada uno de los bienes (títulos de dominio, actas de deslinde y valoración, expediente de adquisición, planos y fotografías, ficha-carpeta, etc.).

Las carpetas llevarán en su solapa igualmente la misma numeración que corresponda a los bienes en el Inventario o en las sucesivas rectificaciones. Este archivador metálico, singularizando la documentación de cada bien en su propia carpeta, facilitará la búsqueda e identificación del mismo.

\section{FICHERO}

El fichero conviene se adapte a las dimensiones de una ficha de $12 \times 20 \mathrm{~cm}$. La ficha solamente deberá contener, tratándose de bienes inmuebles, los datos más elementales: finca, número del in- 
ventario (en el lado opuesto para que se vea con facilidad), escritura, registro, destino, calificación y localización (este último dato en función de planos de situación cuadriculados con ejes de ordenadas y abcisas).

Las fichas deberán estar alfabetizadas de acuerdo con el nombre de las fincas. Cuando las fincas no tengan un nombre propio o notorio se le atribuirá de acuerdo con su situación, el nombre de la calle o entidad de población.

Al figurar junto al nombre el número de la finca, inmediatamente se localiza toda la documentación en su respectiva carpeta.

\section{PLANOS DE SITUACION DEL MUNICIPIO}

En estos planos (escala $1: 2.500$ ó $1: 2.000$ ) deberán figurar los bienes de la Corporación, señalados con distintos colores, de acuerdo con su destino, y junto a ellos, el número que les corresponda en el Libro-Inventario de Bienes, de forma que con este sistema se identifica igualmente la documentación en su propia carpeta.

Estos planos constituyen un elemento auxiliar insustituible.

\section{CARPETA PARA EL ARCHIVO DE PLANOS ORIGINALES}

Naturalmente deberá ser una carpeta de grandes dimensiones, cuando menos de $40 \times 60 \mathrm{~cm}$.

En esta carpeta se ordenarán los planos originales con el mismo orden numérico que les corresponda en el Libro-Inventario y en las sucesivas rectificaciones.

Existe un riesgo o amenaza de desorden en esta materia cuando los planos originales no están debidamente localizados y ordenados.

Frecuentemente, y por razón de las necesidades de los diversos servicios, es necesario facilitar copias de planos (que deberán obrar en sus respectivas carpetas con la demás documentación), y no se debe correr nunca el riesgo de perder el plano original. 


\section{FICHA-CARPETA}

Anteriormente, al referirnos a la documentación que debe obrar en las carpetas para cada uno de los bienes, hemos mencionado la ficha-carpeta, así denominada por sus dimensiones $(22 \times 32 \mathrm{~cm}$.) y forma de carpeta.

Esta ficha deberá contener todos los datos exigidos por el Reglamento de Bienes a los diversos epígrafes del Inventario. Con ello se evita la necesidad de consultar, y trasladar en su caso, el Libro-Inventario, pero además cumplen otra finalidad igualmente importante: al tiempo de confeccionar nuevo Libro-Inventario con los bienes que continúen siendo de propiedad municipal, y que figuren en el Libro-Inventario anterior y en las rectificaciones que se hayan realizado, bastará con ordenar las fichas-carpetas de acuerdo con su naturaleza, sin más modificación que la relativa a la nueva numeración y actualización de precios y traslado a los impresos propios del Libro-Inventario con los mismos datos.

Conviene hacer notar, por último, que al tiempo de practicar un auténtico saneamiento o revisión del patrimonio municipal, es imprescindible levantar plano por plano, debidamente acotado y con especificación de linderos, de todos y cada uno de los bienes inmuebles. Para este trabajo es imprescindible una eficaz colaboración entre quienes hayan de interpretar la documentación que acredite la titularidad municipal y quien tenga la responsabilidad de marcar fielmente las líneas donde corresponda.

En todo caso, el convencimiento de que el patrimonio municipal, con independencia de que se trate de bienes de dominio público o de propios, está al servicio, en último término, de la comunidad $\mathrm{y}$, por tanto, directa o indirectamente dispuesto a satisfacer fines de interés público, obligará a poner un celo especial en su protección, concluyendo que no se puede, ni siquiera, hacer caridad particular con los bienes de la comunidad. 
EXCMO. AYUNTAMIENTO DE MURCIA Inventario de Bienes Inmuebles

Finca: N.०

A - Situación:

Superficie:

Linderos:

Caracteristicas:

B - Fecha de adquisición, costo de la misma y de las inversiones de mejora:

C - Título, signatura de la inscripción, Derechos reales constituidos a su favor o en su perjuicio y Derechos personales:

D. Naturaleza de dominio público o patrimonial y clase de aprovechamiento:

E - Frutos y rentas:

F - Destino:

G. Valor en venta: 
REVL-1974, núm. 184. CREMADES CERDAN, DANIEL. ORGANIZACION DEL ARCHIVO ESPECIAL ...

AYUNTAMIENTO DE MURCIA Inventario de Bienes Inmuebles

Finca:

Superficie: Núm. Inventario:

Escritura:

Registro:

Destino:

Calificacion: Localización:

\section{AYUNTAMIENTO DE}

\section{Inventario de Bienes Inmuebles}

Finca:

Superficie: Núm. Inventario:

Escritura:

Registro:

Destino:

Calificación: Localización: 
REVL-1974, núm. 184. CREMADES CERDAN, DANIEL. ORGANIZACION DEL ARCHIVO ESPECIAL ...

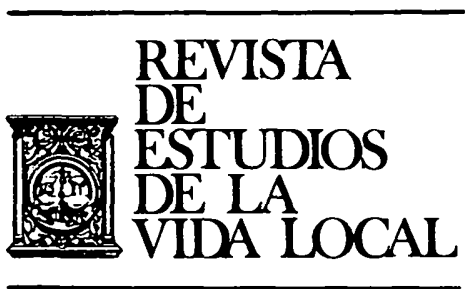

III. ESTADISTICA 
REVL-1974, núm. 184. CREMADES CERDAN, DANIEL. ORGANIZACION DEL ARCHIVO ESPECIAL ... REVL-1974, núm. 184. CREMADES CERDAN, DANIEL. ORGANIZACION DEL.ARCHIVO ESPECIAL ... 